\title{
Is the Triple Bottom Line a restrictive framework for non-financial reporting?
}

\author{
Kaushik Sridhar
}

Received: 26 April 2011 /Accepted: 4 September 2011 /Published online: 6 October 2011

(C) Springer Science+Business Media B.V. 2011

\begin{abstract}
The purpose of this paper is to empirically analyse the developmental stages of non-financial reporting in corporations, by interpreting the views of interviewees from major ethical corporations on the six major dimensions of nonfinancial reporting (identified in the literature) within each stage of the five-stage model of non-financial reporting (developed in this paper). This study is part of a series of papers on Triple Bottom Line reporting (TBL), and its relevance to corporate reporting practices. The TBL is perhaps the pioneer for getting corporations thinking about non-financial reporting. While literature has been done extensively on the TBL framework, empirical data linking TBL and how it has helped, or even hindered corporations progressing through different stages in their non-financial reporting processes is missing. In order to facilitate this analysis, 40 interviews were conducted over 1 year, with 40 corporations selected from various sustainability indexes, focusing on corporations that adopt best practices in this area, and also have a TBL approach to non-financial reporting. The results of the analysis show that TBL certainly got corporations started in the journey of non-financial reporting but has not pushed them far enough to develop a more integrated approach to reporting nor clearly aligning their non-financial reporting performance with their financial performance and business strategy.
\end{abstract}

Keywords Triple Bottom Line $\cdot$ Stages $\cdot$ Non-financial reporting $\cdot$ Corporate social responsibility · Sustainability · Denial · Integration · Stakeholders · Transparency · Accountability $\cdot$ Leadership $\cdot$ Strategy $\cdot$ Disclosure $\cdot$ Corporate culture

\section{Introduction}

In the current economic climate, the traditional and basic accounting frameworks do not represent the holistic performance of a corporation. Non-financial accounting 
frameworks encapsulate better the holism and significance of corporate behaviours, actions and impacts. Corporations that are forward thinking have shifted their paradigm from having a compliance-based strategy towards corporate reporting to a more proactive strategy by focusing more on financial and non-financial reporting. Non-financial reporting is the system of measuring organisational performance in the environment and social (non-financial) dimensions and disclosing this information to internal and external stakeholders. Non-financial reporting drives corporations to be more transparent and accountable with their overall performance, and its impact on the overarching pursuit towards the goal of sustainable development (Hartman et al. 2007; Nielsen and Thomsen 2007). While a number of non-financial reporting frameworks have been developed over the years, the best known framework that numerous corporations globally have embedded into their reporting systems and culture is the Triple Bottom Line (TBL) reporting framework. TBL is conceived as a popular reporting tool describing corporate social, environmental and economic performance. The progression or evolution among corporations who adopt TBL reporting as their main non-financial reporting framework over a period of time is missing in research, and hence, this paper aims to fill that gap.

The purpose of this paper is to empirically analyse the developmental stages of non-financial reporting in corporations, by interpreting the views of interviewees from major ethical corporations on the six major dimensions of non-financial reporting (identified in the literature) within each stage of the five-stage model of non-financial reporting (developed in this paper). This study is part of a series of papers on TBL reporting and its relevance to corporate reporting practices. The TBL is perhaps the pioneer for getting corporations thinking about non-financial reporting. While literature has been done extensively on the TBL framework, empirical data linking TBL and how it has helped, or even hindered corporations progressing through different stages in their non-financial reporting processes is missing. In order to facilitate this analysis, 40 interviews were conducted over 1 year, with 40 corporations selected from various sustainability indexes, focusing on corporations that adopt best practices in this area and also have a TBL approach to non-financial reporting. The results of the analysis show that TBL certainly got corporations started in the journey of non-financial reporting but has not pushed them far enough to develop a more integrated approach to reporting nor clearly aligning their non-financial reporting performance with their financial performance and business strategy.

\section{Literature review}

Evolution of non-financial reporting

The reporting revolution has moved through three phases in history: firstly, in the 1960s and 1970s, corporations tried to minimize the damage caused on the environment from their operations (Makower 1993; Sullivan 1992); secondly, corporations reacted to the regulations put forth by governments in the $1980 \mathrm{~s}$ and tried to reduce their costs of complying with these regulations (Rondinelli 
and Berry 1997; Mirvis and Googins 2004); and thirdly, in the 1990s, with the advent of numerous frameworks such as the TBL reporting framework, corporations found a reporting mechanism to disclose their environmental and social data and use this tool to find ways to minimize their environmental impacts as well as look for new business opportunities through best practices in environmental management.

\section{Dimensions of non-financial reporting}

Within non-financial reporting, six important dimensions have been identified in the literature as major drivers for corporate acceptance or denial of nonfinancial reporting frameworks: the underlying concept or meaning, strategic objectives, leadership, stakeholder focus, level of disclosures and integration. Firstly, non-financial reporting is a broad topic and can have different meanings to different corporations. This is evident in different terminologies such as TBL, corporate citizenship, corporate social responsibility, sustainability etc. Hence, the meaning that corporations attach to non-financial reporting plays a key role in the manner in which they report on their non-financial activities. Secondly, the strategic objective or competitive advantage that corporations can garner from non-financial reporting is a key driver in their need to adopt or abandon this approach (Cummings and Doh 2000; Greening and Turban 2000). Enhanced reputation, brand image, corporate identity with the employees is key elements of adopting non-financial reporting practices. Thirdly, the introduction and implementation of non-financial reporting is driven from senior management, such as the Board of Directors or the CEO of the corporation (Donaldson 2005). Seventy-nine per cent of CEOs agreed that non-financial reporting was vital to the profitability of any company (PricewaterhouseCoopers' Global CEO Survey 2003). The fourth dimension is on stakeholder focus. Corporations are interdependent with their internal and external stakeholders; there are consequences when corporations ignore the needs of their stakeholders leading to public attacks and a possible removal of their licence to operate (Hooghiemstra 2000; Cumming 2001). The fifth dimension is the level of disclosures that corporations need to provide. Since non-financial reporting is mostly voluntary, corporations are not mandated to adopt this practice. However, as mentioned previously, the growing knowledge in this area is creating a sense of awareness and demand from stakeholders to see more non-financial information reported by corporations (Blaconniere and Patten 1994; Roberts 1992). This in turn has made the fifth dimension a compliance issue despite being based on a voluntary topic. The sixth dimension is integration. Over the last few years, corporations have started to appreciate the topic of non-financial reporting more and attempted to integrate it with their financial/annual reports. While unsuccessful, this has proven to be the next step in advancing this area. Literature has shown that integration is potentially the final stage in the evolution of non-financial reporting (Kaplan and Cooper 1998; Schaltegger and Burritt 2000). The integration between social and corporate interests, which leads to business proposals and strategies being informed by the environmental and social data, provides the foundation for an integrated approach. Hence, the six dimensions not 
only individually drive non-financial reporting but also drive it in an integrated manner. However, for the purpose of this paper, the analysis will focus on investigating each dimension individually and how corporations behave within each dimension.

\section{Non-financial reporting frameworks}

During the past 20 years, a voluminous literature on narrative reporting has emerged, together with a number of feasible non-financial reporting frameworks and approaches. Two of the most notable ones are the Global Reporting Initiative (GRI) and the AA1000 Principles Standard 2008. The GRI has put out the G3 guidelines which can be applied to corporations of different sizes and locations (GRI 2006). The GRI and the AA1000 function on a principles-based approach and continue the multi-stakeholder process. There are currently three sets of indicators for reporting in the GRI: core, additional and sector specific (which could, for that sector include 'core' and 'additional'). The distinction between core and additional is based on different presumptions of materiality. There is insufficient guidance in G3 of the reasons why indicators were considered to be core or not (Sherman 2008). The GRI offers a high number of indicators which makes it hard for corporations to determine the materiality or importance of their key issues and its relation to the indicators. The different levels of parameters and indicators allow corporations to handpick those that are important to them leading the issue of selective reporting (Moneva et al. 2006).

\section{The Triple Bottom Line}

The main function of the TBL approach is to make corporations aware of the environmental and social values they add or destroy in the world, in addition to the economic value they add (Henriques and Richardson 2004; Elkington 1997; Berger et al. 2007; Morland 2006). Research indicates that for a variety of reasons, corporations adopting TBL reporting are making changes to the way they do, or at least think about, business (Kimmett and Boyd 2004). TBL has become a dominant approach today in terms of corporate reporting and being more transparent in accounting practices (Robins 2006; Savitz and Weber 2006). A mere 6 years after Elkington's coining of the term, the search engine Google would reveal 52,400 web entries concerned with the topic, and as of 9th September 2009, the number of hits is 1,190,000. According to the Corporate Register database (Corporate Register 2008), the number of TBL reports grew from around 30 in 1992 to more than 1,800 reports in 2008. TBL is considered a metaphor for understanding that the social and environmental areas are important ingredients that contribute to company's success (Morland 2006). However, reporting or any corporate activity hinges on the corporation's licence to operate. Elkington (1997) developed TBL for Shell, a major oil corporation to function as a vehicle to communicate with their external stakeholders. TBL's utility in minimizing damage to corporate reputation and brand and enhancing their image as a socially responsible corporation maintained Shell's licence to operate. This feature of TBL is still present and hence, makes it a strong standard for non-financial reporting. 
Corporations are vigorously creating and publishing TBL reports in order to showcase an image of care for the economic, environmental and social dimensions of social responsibility (Raar 2002; Morland 2006; MacDonald and Norman 2007; Robins 2006). Figure 1 below provides a pictorial snapshot of the factors that drove TBL reporting.

Figure 1 shows examples of some of the rationale for corporate voluntary disclosures. Most business managers are pragmatic individuals, and they see the need to respond appropriately to the changes in the environment; particularly, the increasing awareness, concerns and expectations of their customers and other stakeholders, in order to survive in the long term. TBL reporting is a mechanism or relationship building exercise with an ultimate aim to enhance the corporate financial sustainability in the long term. Non-financial reporting on the other hand is a strategic economic driver that paves the way for future success and sustainability (Healy and Palepu 2001; Verrecchia 1993). In Fig. 1, intangible factors, stakeholder expectations and competitive forces are associated with sustainability of long-term performance. For a number of corporations, social and environmental values have become an important part of their corporate culture (Clarkson et al. 2008). While the impacts of social and environmental performance on financial performance are likely to be less direct and les immediate through TBL reporting, these non-financial impacts would have an intangible value that corporations find hard to discard (Sherman 2009). However, this does not necessarily mean that corporations accept TBL reporting to be a success. Initially, corporations used the TBL approach to measure and disclose their economic, environmental and social performance through TBL reports (Pedrini 2007). However, the ability to see the value add from TBL reporting was invisible to the corporate eye (Sridhar 2011; Norman and Macdonald 2003). The absence of a value add could have potentially pushed corporations to become more proactive and attempt to align their corporate strategy with their sustainability functions and stakeholder expectations by exploring and developing new frameworks. This is further investigated in the findings section of the paper.

In order to try and understand the evolution of non-financial reporting processes of corporations through the lens of TBL, it is important to see where an organisation

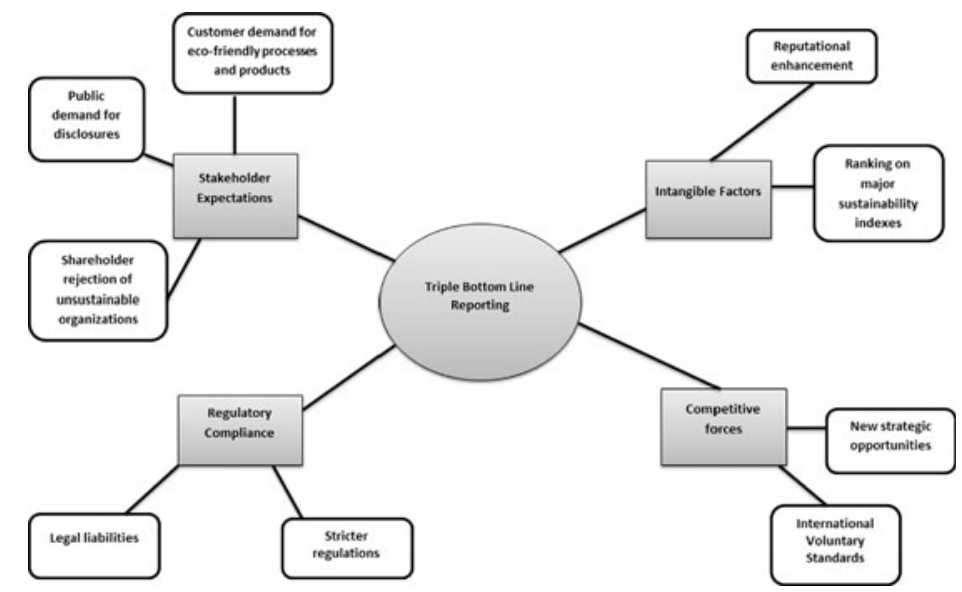

Fig. 1 Forces driving TBL reporting 
has been prior to its TBL adoption and where it intends to go in the future. There are some corporations that are unclear on what non-financial reporting means to them (Robins 2006). On the other extreme, there are some corporations that are trying to integrate their non-financial reporting with their financial reporting in order to set new standards of performance and come up with one-single report. In between the two is a group of corporations that are transitioning in terms of their understanding, values, knowledge and practices about TBL and non-financial reporting. Hence, understanding the stage at which TBL/non-financial reporting currently sits with corporations that seem to show best practice in this area and knowing what challenges they face in advancing their reporting processes can provide a better understanding about where the organisation stands and what strategic choices they have to move forward. This can in turn help in developing benchmarks and targets for the corporations to improve the area of non-financial reporting.

\section{Stages of non-financial reporting}

What is the definition or meaning to say that a company is at a 'stage' in its nonfinancial reporting process? Piaget's developmental theory showed that there are different patterns of operation that happen at each stage of development. These operations or activities become more sophisticated and complex as the development process improves, and hence the capacities to respond to any challenge simultaneously improves (Piaget 1969; Wheelan 2004). From a non-financial reporting perspective, corporations grow along a developmental path as they are faced with challenges (emotional and operational) that need a more socially sensitive framed interaction with the external and internal environment.

The development of stages

A number of models of stages for reporting have been developed in the academic literature. On a large scale, academics have analysed changing views of the function of corporations in society, with the views being nurtured by governments, organisation leaders, scholars etc. (Hart 1997). The research identified the evolution of terms like corporate governance and ethics, social responsibility and environmental management that have become synonymous with the way in which corporations conduct themselves in the community. Other academics have investigated these terminologies further through professional and social movements at the industry and society level (Shrivastava 1992; Elkington 1997). At an organisational level, the level of regulatory demands and stakeholder expectations push corporations to build their capabilities to meet these demands as well as improve their own sustainability policies (Post and Altman 1992). Studies show that organisational learning becomes more complex at different stages of development (Hart 1997; Zadek 2004), as the requirement to act becomes more demanding, as well as the structures, systems and processes to conduct non-financial reporting also becomes more detailed and complete.

However, the limitation in these frameworks is that the mechanisms that motivate the development of non-financial reporting in corporations as well as the logic 
behind it have not been fully explored. Hence, this paper looks at a stage-by-stage process that uses the organisational capabilities (TBL) implemented to non-financial reporting issues and how it has driven development forward (or backward) in a normative sense or logic. Greiner's (1972) model of organisational growth discusses this normative direction. According to Greiner, a number of predictable issues trigger responses from corporations that not only aid in their development process but also help them to move forward. Mechanisms that trigger these responses are simply the problems between the current state of operations and issues that they create that demand an improved response from the organisation. During times of crisis, corporations develop progressive, effective and elaborate responses to the challenges posed to them. This normative model can serve as a foundation for the stages developed in non-financial reporting and TBL. The triggers in the model are challenges requiring a new response. In non-financial reporting, these challenges revolve primarily on an organisation's credibility as a corporate citizen; meet stakeholder needs, the linkage of its reporting processes, and its commitment to embed non-financial reporting as part of its corporate culture and strategy. Under this framework, there is no end point or conclusion, i.e. corporations cannot attain a penultimate end result or stage (Van de Ven and Poole 1995). Hence, the development of non-financial reporting within any organisation is determined by the environmental, socio-economic and institutional forces that have an effect on the organisation.

\section{The five stages of reporting}

The five stages of reporting developed in this paper have been modelled after the work of Dunphy et al. (2003). They have created an evolutionary path which they represent as a phase model. Table 1 illustrates the Dunphy framework:

Ultimately, the goal of every corporation should move into this stage. The goal of becoming a sustaining corporation requires an awareness of the system. Moving beyond compliance, developing new technologies, formulating company values and mission statements based on its sustainable goals are the characteristics of a sustaining corporation. The model in Table 1 provides a way of thinking that can help people determine whether reports are being produced to provide mere compliance or whether they are being used to develop/evolve corporations to higher levels of sustainability. The number of indicators in corporate performance is growing showing a need for diversity and plurality (Schoenberger-Orgad and McKie 2005). The limitation or gap with existing models in literature is the lack of acknowledging the presence of a TBL way of thinking through each stage. Dunphy

Table 1 The phase model (Dunphy et al. 2003)
The phase model

Rejection

Non-responsiveness

Compliance

Efficiency

Strategic proactivity

The sustaining corporation 
et al.'s model encompasses non-financial reporting as a broad area through which corporate behaviours are analysed to see their progress along the different stages. However, for this paper, a five-stage model which is fairly similar to Dunphy et al.'s model is built with the sole purpose of investigating how corporations using TBL reporting in particular were able to progress from stage to stage. While this model is built for investigation from a TBL perspective, it is universally applicable for corporations that conduct sustainability or non-financial reporting.

As mentioned in the 'Introduction', this paper is part of a series of empirical works on investigating and analysing TBL's impact on corporate behaviours and activities over a period of time. Hence, the foundation of literature upon which this model is built is found in Sridhar's (2011) paper on the multi-dimensional criticism of TBL.

1. Stand back and wait approach - a defensive stage

2. Being transparent and accountable - a compliance stage

3. Alignment of stakeholder expectations and corporate strategy-embedding social issues into management strategy

4. Build system based on stakeholder expectations - early signs of integration of social/environmental issues into economic matters

5. A fully integrated approach-transformation and collective action towards complete integration of financials and non-financials.

As the model shows, the first stage is not sustainable, the 2 nd is a reactive phase to stakeholder pressures, the third and fourth stages are showing signs of moving beyond a simple TBL approach, and the fifth stage is the fully integrated goal that corporations aim to achieve. The difference in the five stages shown above and the stages created in other literary works is the empirical focus of these stages purely from a TBL perspective. The five stages are sequential as it provides a logical sequence through which corporations interpret and evolve in their non-financial reporting processes. It would be hard for a firm to jump from stage 1 to stage 5 without understanding the complexities of reporting at stages 2, 3 and 4. The 'Methodology' section will elaborate more on how these stages are interpreted through a TBL lens for nonfinancial reporting and development processes.

\section{Dimensions of non-financial reporting}

In order to track the developmental path of non-financial reporting in corporations, this paper focuses on six dimensions of non-financial reporting, in particular, TBL, and corporate attitudes and behaviours to TBL within each of the five stages mentioned above.

1. TBL concept: how is TBL defined?

2. Strategic objectives: what is the purpose of TBL and non-financial reporting in an organisation? What it is trying to achieve through TBL in terms of business strategy? Corporations normally tend to consider reputational risks and benefits in order to establish a business case for adopting TBL and non-financial reporting. 
3. Leadership: do top leaders support TBL and non-financial reporting? Do they lead the effort? Research, interviews and surveys show that leadership is a catalyst for adopting TBL and non-financial reporting practices in an organisation. However, to what level do the leaders get involved with the reporting activities, are they proactive or reactive?

4. Stakeholder focus: does TBL serve as a tool for them to engage with stakeholders? An increase in the number of non-governmental corporations (NGOs), increased regulatory compliance, increased awareness by shareholders, have all driven the manner in which corporations communicate and engage with their stakeholders.

5. Level of disclosure: how transparent and accountable is an organisation about its TBL performance?

6. Integration: what level of integration is achieved in an organisation's TBL reporting or non-financial reporting process?

An example of how a stage relates to each of the six dimensions is given below (stage 1).

\section{Stage 1: stand back and wait approach}

TBL concept In the stand back and wait stage, corporations are normally faced with intense and possibly unexpected pressures from external sources such as media but also from other stakeholders like their investors or customers. At this stage, corporations tend to deny any wrongdoings against them and reject any negative impacts their activities might have caused. TBL reporting does not play a role at this stage as corporations are not even reactive; they tend to be more resistant to moving forward in terms of their social responsibility. An example can be provided of how an organisation that was one of the early adopters of TBL reporting still functions partially in this stage. Shell, a major oil company, has continued to play a stand back and wait approach regarding its carbon emissions. The organisation rejects concerns and demands by environmentalists, even today, regarding being held accountable for emissions from its products after they have been sold to customers. This is a good example of how corporations adopting TBL reporting do not necessarily have to be very proactive or even fully accountable with their actions as the reasoning behind TBL adoption does not 'necessarily' drive corporations further within the moral grounds of improved CSR or corporate citizenship.

Strategic objectives Corporations tend to prefer being compliant with the general industry regulations and delegate responsibilities of handling these compliance issues with the public relations or legal departments. The function of the departments here is to make sure that corporations follow the rules and avoid any attacks on their reputation.

Leadership Leadership is indifferent to CSR and non-financial reporting matters at this stage. Generally, leaders at this stage focus only on driving profits and satisfying shareholders. Friedman (1970) sums up the notion of this stage by stating that an organisation's obligations to society are solely to make a profit. Smaller-sized 
corporations tend to fall in this stage partly because they do not have the necessary resources to make a larger impact on the communities and the environment.

Level of disclosure At this stage, corporations put out an annual report which primarily encapsulates their financial information. The concept of putting out a sustainability report or a Corporate Responsibility report that provides non-financial information is absent.

Integration At this stage, there is no focus on non-financial reporting, and hence, the concept of integration is still unknown to corporations or they are consciously incompetent with this concept.

Stakeholder focus At this first stage, corporations' non-financial reporting practices are primitive. TBL reporting is relatively absent in the culture within the organisation and most importantly, the channel of communication with the stakeholders is one way, especially in the environmental and social areas.

Hence, within each of the five stages, the six dimensions of non-financial reporting are posed to the interviewees to better understand their interpretation of TBL and how it has helped or hurt their progress or development along the fivestage model.

\section{Methodology}

This study was conducted over a period of 9 months, during which interviews were conducted across 40 corporations around the world that were considered to be following best practices in non-financial reporting. Interviews were necessary as it would lead to a more personal and transparent method to collect data from the interviewees. The key interviewees were managers and heads of the sustainability departments within the corporation. Forty corporations were selected to participate in the study based on a few criteria. Firstly, by looking at different sustainability indexes and projects like the Dow Jones Sustainability Index, FTSE4Good and The Carbon Disclosure Project, it was possible to identify a group of corporations who were considered to follow better non-financial reporting practices by these indexes. For example, the criteria used to rank corporations on the DJSI are based on TBL performance. Hence, narrowing down and selecting corporations (which ended up being 40) who were ranked on ethical indexes, as well as having TBL reporting in the past and/or present were the two main considerations for the selection process for the sample. The 40 corporations were the highest achieving/performing firms in the indexes in terms of their ranking. They are all listed companies with the respective countries' stock exchange. The participants were from different countries around the world as the research aimed to get a mix of data from corporations operating in Australia, America and Europe. The group of 40 corporations is shown in Table 2.

Thirty-one corporations in the sample are based out of Australia. This may seem like a potential limitation with the study as the results may appear to be more Australian focused. However, the fundamental TBL reporting principles is a global 
Table 2 Sample of 40 corporations

\begin{tabular}{|c|c|c|}
\hline Organisations & Industry & Country \\
\hline A1 & Auto manufacturers & Germany \\
\hline A2 & Auto manufacturers & USA \\
\hline A3 & Auto manufacturers & Australia \\
\hline B1 & Beverages & Australia \\
\hline B2 & Beverages & Australia \\
\hline $\mathrm{C} 1$ & Building and construction materials & Australia \\
\hline $\mathrm{C} 2$ & Commercial and professional services & Australia \\
\hline $\mathrm{C} 3$ & Commercial services and supplies & Australia \\
\hline $\mathrm{C} 4$ & Consulting & Australia \\
\hline E1 & Energy & Australia \\
\hline $\mathrm{F} 1$ & Financials & Canada \\
\hline $\mathrm{F} 2$ & Financials & Australia \\
\hline F3 & Financials & Australia \\
\hline $\mathrm{H} 1$ & Healthcare & Australia \\
\hline $\mathrm{H} 2$ & Healthcare & England \\
\hline I1 & Industrials & Germany \\
\hline $\mathrm{I} 2$ & Information technology & USA \\
\hline $\mathrm{I} 3$ & Information technology & Australia \\
\hline I4 & Information technology & Australia \\
\hline I5 & Insurance & Australia \\
\hline I6 & Insurance & Australia \\
\hline I7 & Investment banking & Switzerland \\
\hline M1 & Materials & Australia \\
\hline M2 & Materials & Australia \\
\hline M3 & Materials & Australia \\
\hline M4 & Materials & England \\
\hline M5 & Media & Australia \\
\hline P1 & Print services & Australia \\
\hline R1 & Real estate & Australia \\
\hline R2 & Real estate & Australia \\
\hline R3 & Real estate & Australia \\
\hline R4 & Retail & Australia \\
\hline $\mathrm{T} 1$ & Telecommunications & Australia \\
\hline $\mathrm{T} 2$ & Tourism & England \\
\hline $\mathrm{T} 3$ & Transport and logistics & Australia \\
\hline $\mathrm{T} 4$ & Transport and logistics & Australia \\
\hline T5 & Transportation & Australia \\
\hline T6 & Transportation & Australia \\
\hline $\mathrm{T} 7$ & Transportation infrastructure & Australia \\
\hline U1 & Utilities & Australia \\
\hline
\end{tabular}


phenomenon and the acceptance and implementation of TBL has no boundaries. The corporations in this sample discuss their TBL reporting techniques from a holistic perspective and not from an objective point of view. This would be a limitation if the study was done on environmental or social measurement techniques/practices only. The corporations selected in the sample have signed the agreement for interviews conditional upon the organisation's name and the interviewee's name being kept confidential. Hence, a company code has been assigned to individual corporations. As shown in Table 2, the annotation for each corporation is correlated to the industry that they are in. Hence, the corporation that is in the Utilities industry is coded as 'U1' while a corporation in the Financials industry is coded as 'F1.' In addition, corporations have clearly stated in the agreement form that details of their operations, including market cap, number of employees etc. should not be revealed in the research.

\section{Interviews}

The interviews were conducted in person as well as over telephone and the interview questions were structured and developed from the literature survey and analysis. The questions were structured around the five-stage model, initially asking the organisation what stage they were operating in at present, and where they wanted to get to in the future. Table 5 in the Appendix shows the list of interview questions. Based on the responses to the two questions, corporations were then asked to elaborate along the six dimensions for each stage, to get a better understanding of how and why they operated at each stage. Fundamental to each question is the importance of TBL reporting and how they perceived its function at each stage. Once the interviews were completed, they were transcribed and analysed using NVIVO and Excel to not only determine how many corporations were at each stage, but also try and collate data around each dimension using coding. Table 3 summarizes interviewees by job title.

\section{Findings}

Tables $6,7,8$ and 9 in the Appendix provide a summary table of responses to the interview questions. The first question posed to the interviewees was to identify which stage they were in terms of their non-financial reporting. Based on the interviewees' verbal responses, Table 4 below shows the results for how many corporations belong in each stage:

All 40 corporations wanted to ultimately reach a 'fully integrated approach' in the near future. The above data show the lack of integrated thinking in the TBL framework, as these corporations began their journey with a TBL reporting style. Stages 3 and 4 in the model are interchangeable and hence, 14 corporations are executing both the stages through their engagement process as well as developing their business strategy. The eight corporations that are 'transparent and accountable' are relatively new in their sustainability journey and are aiming for ways to get to stages 3 and 4 within the next couple of years. The question was posed as to whether the corporations saw themselves as reporting in between the stages; the unanimous 
Table 3 Job title of interviewees

\section{Organisations}

A2

A3

B1

B2

$\mathrm{C} 1$

C3

C4

E1

F1

F2

F3

H1

$\mathrm{H} 2$

I1

I2

I3

I4

I5

I6

I7

M1

M2

M3

M4

M5

P1

R1

R2

R3

R4

T1

T2

T3

$\mathrm{T} 4$

T5

T6

T7

U1
Job title of interviewees

Director, corporate and governmental affairs

Director, sustainability and environmental policy

Manager and environmental policy

Sustainability manager

Sustainability leader

General manager, corporate affairs and investor relations

General manager, environment and climate change solutions

Group manager, environment

Director, corporate citizenship

Manager-investor relations and external affairs?

Manager, corporate responsibility and sustainability

Manager corporate responsibility reporting?

Senior advisor and sustainability

Corporate responsibility associate

VP and corporate responsibility

Director and corporate citizenship?

Manager and corporate affairs

Environmental manager

Regional director

General manager corporate affairs

Manager and business sustainability

Director and sustainability affairs

Sustainability analyst

Sustainability energy officer

Sustainability manager

Global director and sustainability

Director and sustainabilty

Manager environment and sustainability

Sustainability manager?

Sustainability manager

Coordinator, corporate responsibility and sustainability

Sustainability manager?

Group manager environment?

Head of sustainability

Senior communications advisor

General manager, CR and quality

National manager environmental sustainability planning

Manager, risk and sustainability reporting

Strategy and marketing manager

Manager and reporting 
Table 4 Number of corporations at each stage of the five-stage model

\begin{tabular}{ll}
\hline Stage & $\begin{array}{l}\text { Number of } \\
\text { companies }\end{array}$ \\
\hline Stand back and wait approach & 0 \\
Transparent and accountable & 8 \\
Alignment of stakeholder expectations and & 12 \\
$\quad$ corporate strategy & \\
Build system based on stakeholder expectations & 6 \\
A fully integrated approach & 0 \\
Stages 3 and 4 & 14 \\
Total & 40
\end{tabular}

response was that transitioning was occurring but at a very small scale. Largely, they were reporting at only one stage and not in between stages.

A more in depth discussion is now given on each stage and how the six dimensions were perceived by the 40 corporations for each stage, in addition to the mechanism of TBL and whether it played an integral role or not. The first stage has no interview data as none of the corporations could relate to a passive approach as they are all well into their journey in non-financial reporting.

Non-financial reporting at each stage

Table 4 provides the stages of development of non-financial reporting along the six dimensions. Each stage is explained below with empirical evidence from organisational interviews as examples of corporate practice.

\section{Stage 2: being transparent and accountable}

TBL concept The birth of TBL reporting is apt to mention at this stage. Its principles and framework functions as a starting point for corporations to begin the dialogue with the stakeholders and embrace a certain level of engagement. TBL's policy-based approach drives corporations to adopt it so as to avoid litigation and reputation damage. Through TBL, corporations are able to provide more visibility on their environmental and social actions and reactions, simultaneously becoming internally aware of their own impacts on these areas. The birth of TBL allowed for policies on environmental practices, employment health and safety etc. to play a more prominent role in organisational reporting and operations.

From an economic point of view, managing sustainability in the company is important. It's easy for operational managers in the business to not believe in the 'green' initiative unless there is a financial outcome or benefit for the company. They perceive more as a cost for the company. From an economic point of view, any sustainability initiative we make must have an economic driver and TBL has initiated this process [Quoted from T5]. 
Strategic objectives At the stage of being transparent and accountable, an organisation aims to be more engaged and compliant with the environmental and social areas, in addition to the generic financial and industry regulations. During this stage, corporations formulate their policies and aim to refrain from doing what they promised not to do. Compliance is interpreted as the cost of having a licence to operate; it generates value for corporations by safeguarding their reputation and minimizing risks and liabilities.

The reason for adopting TBL reporting started from external pressures. We had market pressures from activist groups, and their request for information. It was in 2000/01 that we saw it is difficult for us to report on this area but if we wanted to report it externally, we needed better measures [Quoted from C2].

Leadership During the stage of being transparent and accountable, leadership at an organisation is essential. Their ability to initiate awareness and transformation in the organisational outlook for the employees towards embracing social responsibility is of the utmost importance.

At the moment, TBL is seen as a way for leadership to engage with stakeholders externally as well as driving awareness within the business [Quoted from M3].

Level of disclosure At this stage, the idea of a non-financial report is being conceived but the notion behind this development is still hinging on functioning as a public relations stunt. TBL certainly drives this thinking forward.

Integration The limitation within TBL and this stage is that corporations still tend to be reactive to emerging non-financial matters, rather than being proactive, which limits an integrative manner of thinking and reporting.

We do not have what you would call an integrated accounting framework that brings the TBL together and comes out with some sort of holistic metric that captures all those things. We have financial accounts and we have separate environmental accounting systems. They are more objective and rigorous. The social area is not accounted for properly [Quoted from I5].

From a philosophical perspective, we view that being a good corporate citizen is a driver of our business. Hence, conceptually, we view it as integrated but in terms of measurement, we are some way off [Quoted from I7].

Stakeholder focus The idea of having an interactive communication process with stakeholders appears in this stage. An example of this case comes from $\mathrm{C} 1$ :

When the company was challenged by environmentalists over improper environmental practices, there were conflicting responses from the various internal stakeholder groups within the organisation. It thereupon adopted TBL reporting to immediately address all the environmental and social issues. The important and 
strategic trait displayed in this stage is the desire of the organisation to maintain its licence to operate, preserve its reputation.

However, the hindrance to this is that corporations tend to believe that the expense of efforts and energy to be transparent and accountable as well as have a two-way communication with stakeholders is not worth the expense in financial terms.

\section{Stage 3: alignment with stakeholder expectations and corporate strategy}

TBL concept The correlation between TBL and this stage highlights the problem that corporations have to make a business case for non-financial reporting. Within TBL, the metrics and criteria tend to be functionalized at the third stage. Corporations tend to view benefits of TBL only in particular areas:

- Social-reputation, recruitment and retention.

- Environmental-life-cycle costs

- Economic_risk exposure, access to resources and capital

At this stage, corporations start to realize that they face a long-term problem, which simply cannot be outmanoeuvred through attempts at conducting public relations events or being compliant. TBL reporting represents both these activities and corporations need to think beyond a TBL approach in order to start moving to the next stage. TBL allows corporations to be compliant with certain environmental and social standards; however, what TBL does not show is that such compliance is hard to achieve without proper alignment and of business operations to stakeholder concerns and expectations.

Our decision to get involved in TBL reporting was more about our stakeholders asking us to be more transparent about what we do and how we are performing from a much broader perspective [Quoted from I6].

Further explanation of TBL with the $3^{\text {rd }}$ stage is given under Integration.

Strategic objectives Socially responsible investment houses and indexes, such as the Dow Jones Sustainability Index, have recognized the importance of TBL and rate corporations based on the extent to which they adopt and apply TBL reporting.

It's very important, as it is an external validation of what we are doing. Last year our report was externally assured so there was that credibility. Having that external recognition like DJSI and FTSE is important for us [Quoted from M1].

It is important for us to be ranked. When we fill the questionnaires we know we may be weak in a certain area even before we are told. We are not being compared with companies in other industries though. We are compared with other banks. We were on leadership index of CDP and we used that to our advantage to put it in every press release and get some mileage out of it [Quoted from F1].

As a manager, it is very important. If we come last, that will have a negative effect [Quoted from C3]. 
This has certainly been a stimulus for the continued rigor in reporting practice of TBL in many large corporations.

Leadership Leadership, at this stage, tends to stress the strong value and power of the corporate brand, using TBL as the vehicle to launch this praise. The corporations that are moving their non-financial reporting processes and practices to this stage emphasize the importance of having a top-down leadership approach. TBL reporting, as well as the move towards better alignment and integration are concepts that top management need to drive into the corporate culture.

Leadership is initially important to drive this issue. Once people start seeing the process with their own eyes, then it gets easier. It is a painful process. Once we integrate after getting data to show that this has benefit to company, then people start to realize that they cannot do balance sheet without looking at non financial information. Now we have people from different departments working together [Quoted from R4].

Level of disclosure TBL is aggressively pursued and adopted as a reporting framework for corporations in this stage. Hence, they put out a proper nonfinancial report using TBL principles, and disclosing their economic, environmental and social performance. When indexes like the DJSI use these three criteria of TBL (economic, environmental and social performance) for including corporations, it certainly does not hurt the reporting company from disclosing information using a TBL approach.

Integration In the third stage, corporations aim to take their non-financial reporting practices as well as their CSR practices further by adopting a more integrative approach to non-financial reporting, as well as deepening their commitment and involvement in the area.

We all have a duty to have our shareholders first and foremost. We are making a connection between environmental and social and we know that it's good for business. Engaging our employees and letting them know how we are dealing with the environment is important for us. We're not just spinning our wheels, but that our TBL programme does pay for more than the bottom line. In terms of impact, we know that it's good for business and reputation and clear that we do support corporations that can be tied back to a financial outcome for our business. We do not have a good sense of impact or integrated efforts among the different areas. For example we do not factor in a lot of costs into our donations or volunteer hours, as we do not know what it would cost us in dollars and cents [Quoted from F1].

Corporations at this stage are still hindered though in terms of providing integrated reporting, especially in the social area. They still compile data that are put together by different operating units and presented with a corporate spin, which is essentially what TBL reporting is. A number of financial scandals and legislation led to TBL reporting becoming a 'best practice' in non-financial reporting for corporations. However, the level of integration and alignment with stakeholder 
needs, supply chain performance, and tying all the environmental, community and economic practices and impacts together are still missing in reporting.

Stakeholder focus An important prerequisite for corporations to improve their reporting capabilities in this stage is to increase their two-way communication with a wide range of stakeholders. While this may seem like an important prerequisite for each stage, the best method to try and align reporting that combines stakeholder focus and corporate strategy. For example, A2 conducted a major participation programme with its internal stakeholders to develop a set of revised corporate values and new CSR business principles. This led to an initiative of turning one of their manufacturing plants, that was old and near redundant, into a model of ecoefficiency. This is an example of creating integration between stakeholders and corporate values.

\section{Stage 4: build reporting system based on stakeholder expectations}

TBL concept The fourth stage of building a reporting system based on stakeholder feedback and expectations is a continuation of the third stage, and they can go hand in hand. While the previous stage is where corporations adopt TBL to accept the logic of capitalism from multiple stakeholders as well as accepting the social environmental and economic sustainability to continue their licence to operate, the fourth stage requires developing a system from the ground up purely based on stakeholder interactions and feedback. This in turn provides a greater level of integration right from the beginning. This is the stage at which corporations need to start thinking beyond TBL for their reporting framework and guideline.

Strategic objectives In addition to the strategic objectives mentioned in stages 2 and 3 , corporations emphasize the importance of value add in this stage. Similar to stage 3 , corporations want to see business costs and impacts from their CSR practices and non-financial reporting.

Leadership In order to begin building an appropriate reporting system, an organisation needs to first understand the concept of CSR and sustainability for their organisation, and an integrated system needs to be put in place from the top levels of management, especially commitment from the board level.

I would like to see it as a normal reporting requirement and also see that it sits within our annual report. It should be embedded into the finance, hr, and sales departments and with the senior management team. We should report on material issues only, and show a roadmap of stakeholder issues for us [Quoted from T2].

Level of disclosure A key challenge that is sought to overcome in this stage (for disclosure) is assurance.

When we share our stories through reporting, stakeholders can check through third party assurers and know what we are all about. Are we doing what we say 
we are doing? They can see that third party assurance. It will then improve our corporate reputation [Quoted from A2].

Corporations that produce non-financial reports aim to get it externally verified in order to truly embed accountability into its business.

Integration The biggest challenge here is to move the organisation from a phase of coordination (Stage 3) to a phase of collaboration (stage 4). In stage 3, the presence of TBL reporting in corporations allowed their recognition and reputation to get enhanced on ethical indexes like the DJSI. However, in this stage, corporations looking to move beyond a TBL approach are starting to look at broader integrative systems for their non-financial reporting mechanisms, such as: risk management systems, consultation with stakeholders on a major scale, training internal stakeholders on the importance of sustainability and non-financial reporting and 'issues' management frameworks.

Integration would be great but it's not that easy to accomplish. Having a scorecard approach at the moment complies with a TBL way of thinking but integration certainly does not relate to TBL [Quoted from I2].

Stakeholder focus While a two-way communication focus is still an integral part of this stage, changing the mindset of corporations from simply communicating with their stakeholders, to developing more of a partnership with the stakeholders (especially the external ones) is a central theme for this stage. By renaming stakeholders as partners, an organisation is in turn accepting them into its corporate boundaries, and shows a proactive approach towards building the non-financial reporting system as well as the CSR practices in general.

\section{Stage 5: a fully integrated approach}

TBL concept An organisation should aim to revolutionize its reporting but it should not change what it does just for the sake of reporting but take a more strategic approach. Companies are now starting to question how much they are doing and what 'system' to use? While TBL philosophy is germane to what many companies do, the systems that capture data are not making it easy for employees. Even though the intent and philosophy is right, companies pay a high price internally for the benefits they are getting. The intent of TBL is to draw from non-financial information and draw it all back to financial information. Corporations are supposed to look at non-financial information from a financial perspective based on a TBL way of thinking. Hence, how can an organisation measure something in terms of dollars when there are no dollars attached to say, employee engagement? They cannot do it unless they can show an increase employee engagement which coincides with increase in employee performance. Then again this is just a correlation but there will be so many other factors showing improved performance. How can an organisation put a financial number on reputation or brand image? The manner in which the financial community wants to enforce and interpret TBL is 
flawed since every business is interpreting TBL itself. Hence, the reporting structure itself needs to have a radical change.

Strategic objectives Corporations need to drive integration into the strategy and achieve the emancipation of the environmental and social dimension against the financial dimension. It is hard to see such an approach today based on how large corporations are setup. They need to get the people to work together and then they see other people for information and see impacts. When the companies do financial risk analysis, non-financial data should be looked at. Once the attitude changes and the company can see a value add to the business, then things become easier. In the future, there would not be a need for a separate sustainability report. The business operates sustainably and they will not need to talk about TBL issues in a separate report. Hence, having one approach across all divisions and having it integrated with financial data, and having every single staff reporting against the same framework would be the recommendation. Corporate strategy is what drives the way corporations do business. If they have that core perspective embedded in their culture, then moving forward and taking a broad perspective becomes embedded into the strategy.

Leadership Leadership is initially important to drive this stage. A fully integrated approach would be getting full support from senior management as well as have a top-down and bottom-up approach. To be fully integrated, an organisation would have to have everyone on board.

The discussion for integrated reporting has been driven more from the bottom [Quoted from B2].

In old fashioned we followed a napoleon format and did what we were told to do. On safety, you can tell people about safety but they will never realize it until they see that it's for them and they can take pride from it. That's a huge leap. Hence, a top-down approach is not the best way to go about this. In the beginning, you need a top-down approach to tell you what to do. Then you need to step back and let people buy into it and drive it [Quoted from M4].

The data from the interviews back this principle and show that corporations need to step back and led integrated reporting arising through a holistic discussion and participatory environment rather than a bureaucratic style of management.

Level of disclosure As mentioned before, a single, comprehensive report detailing the financial and non-financial information is the level of disclosure that should be achieved at this stage.

Integration A fully integrated approach would be where a company has a number of tools and a system so that their reporting is complete with no holes and is a seamless process that does not involve as much time as it does now. There is also a firm understanding among employees that the reporting is a reflection of a company's ability to thrive.

Bringing the financial and non-financial report into a single report is the ultimate goal of the Fully Integrated approach. Integrating impacts among the areas is the first 
challenge in trying to achieve a single report. Sustainability must be integrated into business strategy so that if an organisation looks at different impact areas, they can see that sustainability is a part of these different issues. When companies talk about things they want to do in the community, they talk about dollars and cents in donations but they do not have a good grasp on what it is that they do contribute in terms of volunteer hours etc. For example, an organisation has a donations committee and donating to a cause that they have been donating to the past is not a reason for them to keep doing it. There needs to be business impact and business logic to keep doing it. TBL has not helped in the integration process as there is no proper bottom line or aggregating method.

It's not all black and white. The annual report to shareholders and financial stakeholders contains a lot of environmental and social data but does not contain the full data of the sustainability report as there are different needs and requirements of stakeholders from financial world and the rest of stakeholders [Quoted from A1].

In addition, the non-financial reports have to demonstrate that there is a link between the two and not an overlap. Most corporations are good at financial side. Financial matters will have implications on non-financial matters and not the other way around. Once people start seeing the process with their own eyes, then it gets easier. Once they integrate after getting data to show that this has benefit to the company, then people start to realize that they cannot do a balance sheet without looking at non-financial information.

We take a more holistic approach to business sustainability where we need a good financial performance but that needs to be complemented by a whole raft of $\mathrm{CR}$ activities. An integrated approach is one that provides enough information to the external environment of business so that the person reading can see how sustainable the business will be in the coming years, maybe 5 or 10 years from now. It's not just based on dollars and cents [Quoted from T4].

Stakeholder focus An integrated approach is one that provides enough information to the external environment of business so that the person reading can see how sustainable the business will be in the long term rather than the short to medium term. In addition, the concept of strategic alliance should be the terminology for stakeholders in this stage. In stage 4, partners were the term used to refer to stakeholders. However, forming a strategic alliance with them not only symbolizes a level of integration right from the beginning, the value add that corporations want to see in this stage would dramatically increase as the strategic Alliance brings together mutual collaboration of strategic planning and management in order to achieve longterm objectives between the organisation and its strategic ally.

\section{Discussion}

The five-stage model was introduced to each of the 40 corporations interviewed in the sample to determine which stage they believed they were in, and which stage 
they wanted to get to in the future. After looking at the different stages, the corporations believed unanimously that they wanted to get to stage 5 in the future. At present, they are scattered in between stages 2 and 4. How does the transition occur for corporations who hope to get to the next stage from where they currently sit at?

How to evolve in the five-stage model

\section{Transitioning to the second stage}

An organisation will start to think about the second stage only when a major hit is taken against its reputation. For example, an organisation that is making billions in profits intentionally dumps a large amount of toxic materials into a river. When questioned, leadership at the organisation would get defensive and state that at the time of the dump, they had fully complied with the environmental laws existing then. However, the pressures from external groups and the negative publicity of the organisation will serve as a trigger to push the organisation to a new stage in CSR as well as its reporting practices. Embedding a sense of awareness into an organisation due to public expectations and pressures, depicts a readiness to transition from being a passive member to developing a slightly higher level of engagement within the realms of CSR through improved levels of non-financial reporting.

\section{Transition to the third stage}

The level of engagement drives the transition to the next stage with stakeholders and how meeting their needs can be aligned with the corporate strategy, i.e. the ability to be prepared to meet new opportunities and threats. Different stakeholders have different needs and interests and trying to integrate that with corporate strategy is a problem within the TBL framework. The key concept to allow for the transition is innovation. Corporations need to not only report on their social, environmental and economic activities, but they also need to enlarge their capacities to manage the impacts, achieve complete transparency, be ethical, and also see the business aspects of conducting the non-financial reporting activities. TBL allows corporations to report extensively on the three dimensions, but it does not limit corporations from still acting in unethical or degrading ways for the environment or the communities.

\section{Transition to the fourth stage}

The problem in this stage is the number of different activities corporations need to execute, whether it is in creating and launching new programmes in CSR, increase in public requests for information and disclosure which increases their exposure, as well as dialogues with diverse stakeholder groups. Having so many different functions can lead to misalignment and a serious lack of strategic focus. The efforts undertaken by the corporations to systematically manage and coordinate these 
different activities depict the growing strain between integration and differentiation. While this stage certainly shows hints of integration, the journey towards having an integrated approach to reporting and towards CSR practices is still a dream for all corporations. The most common reasons highlighted by the corporations for a lack of integration include:

- Lack of institutionalization of non-financial reporting throughout the business

- The terminology of non-financial reporting, CSR and sustainability have not been clearly or comprehensively defined or articulated to corporations, even with TBL.

- Different functional units within the organisation do not see the value add of working together towards integrated non-financial reporting

- Short-term focus on profits is still the driving force in this stage, and TBL has not changed this attitude at all.

The above points are all interrelated in that the lack of having a proper nonfinancial reporting system stem from each of the four problems mentioned before.

Corporations seem to portray characteristics within each stage to a certain degree, such as being compliant in one area while being proactive and innovative in another area. Hence, while the five-stage model presented in this paper depicts a normative road in the development of non-financial reporting in an organisation, there are a number of factors that determine the direction in which the non-financial reporting practices evolve within the organisation. Based on the data from the interviews, key factors have been discussed below to understand why an organisation chooses to stay or move forward with its non-financial reporting practices, especially regarding their view on TBL.

\section{Corporate mission and vision}

Corporations' reporting practices that are created on a foundation of TBL tend to ignore the first two stages, and move on directly to the third stage. Being defensive or reactive is not in their culture; the organisation and its leaders tend to be proactive with their environment and respond in creative and innovative manners.

\section{External drivers}

A number of socio-political and socio-economic divers play a major role in influencing the non-financial reporting processes and practices of corporations, as well as determining where the gaps are in the organisation's reporting structure. Firstly, corporations in the materials industry (in the sample) are closely monitored by environmental activists and NGOs and hence, are exposed on their environmental activities and impacts. Hence, these corporations pay a great deal of attention to their environmental performance and reporting. A scan of the reports of these corporations in the materials industry showed that the metrics and policies were more geared towards the environmental area, compared with the other corporations. Secondly, corporations in the sample that had a large 
supply chain or labour force in third-world countries, focused more heavily on the fairness of employment, proper working conditions etc. Thirdly, corporations that frequently interacted with indigenous people in Australia had an advanced system for community and stakeholder communications. Fourthly, the regulations and laws enforced by powerful bodies also determine (compliance) how embedded is non-financial reporting in corporations. In the sample, financial corporations tend to provide micro-financing to communities in poverty-stricken countries where they operate due to various community banking provisions put in place by the government, especially in the USA. Finally, the national origins of the corporations also play an important role in how corporations execute their CSR strategies. Corporations based in the USA are quite active in community affairs as they see additional benefits from this participation, which is something European and Asian firms do not. However, the European countries' governments adopt and enforce programmes for social improvement a lot more than that of the USA. Hence, European corporations have an upper hand in adopting and implementing integrated reporting frameworks and concepts, and are much more advanced in the areas of environmental and social reporting, compared with their American counterparts.

Strategy and competitive advantage

Competitive and strategic drivers play an integral role in determining how corporations evolve with their CSR strategies and their non-financial reporting practices. Leaders are increasingly seeing the impacts that their business strategies have on their non-financial reporting agenda. The path that an organisation takes in its reporting determines also who its stakeholders are and how they will react to the corporations' non-financial performance and disclosures (Jawahar and Mclaughlin 2001). This notion explains why corporations in different industries have different non-financial reporting processes and TBL strategies. For example, the large corporations in the sample emphasized the importance of government and local communities in that they played a major force in their business operations and decisions. The same could not be said of a small- to medium-sized organisation. Large corporations also stressed the interpretation of being a good corporate citizen in the community. Finally, the corporations' executives maintained the view that they need to take a more proactive approach in addressing important problems like human rights, climate change etc.

\section{Leadership and corporate culture}

Embedding TBL into the corporate 'DNA' is a sure fire way to keep the organisation's culture stable against constantly evolving pressures in the environmental and social areas. In order to have this trait, leadership is crucial. This is apparent in stages $2-4$ in the model. However, the improvement in the non-financial reporting and TBL practices need to also be driven from middle management as well as from lower layers of 
management. The flow needs to be upward and outward, rather than purely downward.

\section{Conclusions}

This paper has not attempted to deconstruct the TBL from the perspective of putting a nail into its coffin. TBL and other reporting systems that currently exist provide a pathway for corporations to easily ignore or bypass key sustainability issues for couple of reasons. Firstly, corporations that wish to put on a facade of compliance and showcase themselves as embracing the sustainability movement can use any one of the current reporting systems to mask themselves from the external pressure to be more sustainable (Etzion and Ferraro 2009). Due to the absence of mandatory standards, corporations handpick those metrics that they can easily measure and disclose information on these metrics while ignoring those that cannot be measured or those that could possibly show a darker side of the corporation in terms of their sustainability initiatives. Secondly, and more directly towards the TBL reporting system, a lack of integration exists among the TBL principles as each principle is independent from the other in terms of its measurement. The pressure on corporations to show links or inter-relationships between these three principles and how one can affect the other is absent (Hubbard 2009). Hence, corporations show separate data on each of the three principles and assume that they are doing a favour to the external environment, when the data are hard to understand as there is no systems thinking here.

TBL will be around for some time to come. It is a convenient tool for competitive business operating in an environment characterised by progressive learning. The benefit to be gained from TBL approach is not so much in the reporting, but in the understanding of the meaning of what is being reported. The argument is that integration of social, economic and ecological considerations are the essence of the concept of sustainability and must be a central consideration in the design and implementation of sustainability-based assessment. It would be fair to rename TBL as IBL or integrated bottom lines, as other issues like culture and corporate governance, are bottom lines that should be factored into the calculation, if the social indicator is given such importance. Coverage of social impact among various measurement systems is inadequate, and the concept of TBL does nothing to enhance the measurement of social bottom lines. The TBL approach fits poorly with the concerns commonly expressed by citizens who are the intended beneficiaries of strategic and project level undertakings. Based on the analysis done in this paper, it does seem that continuous development of non-financial reporting principles and processes in an organisation is unbounded. The challenges of commitment, collaboration, capacity and credibility need to be conquered in order to develop a more integrative approach to non-financial reporting. Due to the universal value of TBL and non-financial reporting, corporations will certainly move forward by adopting a more fully integrated approach and in doing so, will raise the bar for their competitors and the industry as well. 


\section{Appendix}

Table 5 List of interview questions

1. What does the Triple Bottom Line mean for your business, and why is it important?

2. Do you see it as a metaphor or a new accounting metric?

3. Does TBL guide you to be compliant and did you have think beyond TBL to go beyond compliance?

4. What are the core characteristics of a TBL report in your corporation?

5. What were the main benefits of TBL reporting: tangible vs. intangible?

6. How important is it to be ranked on sustainability indexes?

7. Have you experienced problems implementing TBL reporting?

8. Are there any integrating methods that your company has that make the TBL data more readable?

9. Do you choose indicators to measure key concerns of stakeholders, or do you choose

10. To what extent does the corporation focus on the social dimension of the TBL?

11. Do you have a social net profit or loss; would you like to have one?

12. What stage are you in the reporting system:

(a) Stand back and wait approach

(b) Transparent and accountable

(c) Alignment with stakeholder expectations and corporate strategy

(d) Build system based on stakeholder expectations

(e) A fully integrated approach

13. How would you define a fully integrated approach?

14. Which factor drives your desire to become socially responsible and embrace sustainable development and TBL reporting: prosperity of the corporation, or greater responsibility which drives prosperity?

15. How important has leadership been for driving sustainability reporting?

16. Is there anything that you do not prefer to report on but are motivated to report?

17. How would you like to see reporting evolve at your corporation?

Table 6 TBL's importance to corporations

\begin{tabular}{llll}
\hline Company coding & TBL mentions & Q1-importance & $\begin{array}{l}\text { Q2-metaphor/accounting } \\
\text { metric }\end{array}$ \\
\hline A1 & 0 & Not important & Metaphor \\
A2 & 0 & Only bottom line & Metaphor \\
A3 & 0 & Engagement process & Metaphor \\
B1 & 0 & Balancing act & Metaphor \\
B2 & 0 & Follow competitors & Metaphor \\
C1 & 0 & Raised awareness & Metaphor \\
C2 & 0 & No meaning to us & Metaphor \\
C3 & 0 & Do not limit to TBL & Metaphor \\
C4 & 0 & Meaningless phrase & Metaphor \\
E1 & 0 & Licence to operate & Metaphor \\
F1 & 0 & Not in the language & Metaphor
\end{tabular}


Table 6 (continued)

\begin{tabular}{|c|c|c|c|}
\hline Company coding & TBL mentions & Q1-importance & $\begin{array}{l}\text { Q2-metaphor/accounting } \\
\text { metric }\end{array}$ \\
\hline F2 & 0 & Awareness of CR & Metaphor \\
\hline F3 & 0 & Never TBL; stakeholder impact report & Metaphor \\
\hline H1 & 0 & $\begin{array}{l}\text { None; GRI because other companies } \\
\text { use it }\end{array}$ & Metaphor \\
\hline $\mathrm{H} 2$ & 0 & Beyond TBL & Metaphor \\
\hline I1 & 0 & Compliance process & Metaphor \\
\hline $\mathrm{I} 2$ & 0 & External pressures & Metaphor \\
\hline I3 & 0 & Not in the language & Metaphor \\
\hline I4 & 0 & No TBL; outcome focused & Metaphor \\
\hline I5 & 0 & Broader perspective & Metaphor \\
\hline I6 & 0 & Broader perspective & Metaphor \\
\hline I7 & 0 & Use corporate citizenship, not TBL & Metaphor \\
\hline M1 & 0 & 5 domains - no TBL & Metaphor \\
\hline M2 & 0 & Follow competitors & Metaphor \\
\hline M3 & 0 & Engagement process & Metaphor \\
\hline M4 & 0 & TBL was reactive; now more proactive & Metaphor \\
\hline M5 & 0 & Good starting framework & Metaphor \\
\hline P1 & 0 & Beyond TBL; more holistic & Metaphor \\
\hline R1 & 0 & Raised awareness & Metaphor \\
\hline $\mathrm{R} 2$ & 0 & Materiality & Metaphor \\
\hline R3 & 0 & Not a driver & Metaphor \\
\hline R4 & 0 & Raised awareness & Metaphor \\
\hline $\mathrm{T} 1$ & 0 & Outdated concept & Metaphor \\
\hline $\mathrm{T} 2$ & 0 & External pressures; trend from business & Metaphor \\
\hline $\mathrm{T} 3$ & 0 & Business benefits & Metaphor \\
\hline $\mathrm{T} 4$ & 0 & Pinning business costs on env/soc & Metaphor \\
\hline $\mathrm{T} 5$ & 0 & Compliance & Metaphor \\
\hline $\mathrm{T} 6$ & 0 & Compliance process & Metaphor \\
\hline $\mathrm{T} 7$ & 0 & External pressures & Metaphor \\
\hline U1 & 0 & Compliance process & Metaphor \\
\hline
\end{tabular}

Table 7 TBL as a reputational factor

\begin{tabular}{lllll}
\hline $\begin{array}{l}\text { Company } \\
\text { coding }\end{array}$ & $\begin{array}{l}\text { Q3-compliance/ } \\
\text { beyond compliance }\end{array}$ & $\begin{array}{l}\text { Q5-tangible } \\
\text { vs. intangible benefits }\end{array}$ & $\begin{array}{l}\text { Q6-ranking } \\
\text { importance? }\end{array}$ & $\begin{array}{l}\text { Q9-stakeholder focus or } \\
\text { corporate strategy? }\end{array}$ \\
\hline A1 & Compliance & Intangible & Yes & Combination \\
A2 & Compliance & Intangible & Yes & Combination \\
A3 & Compliance & Intangible & Yes & Combination \\
B1 & Compliance & Intangible & Yes & Combination \\
B2 & Compliance & Intangible & No (due to merger) & Combination
\end{tabular}


Table 7 (continued)

\begin{tabular}{|c|c|c|c|c|}
\hline $\begin{array}{l}\text { Company } \\
\text { coding }\end{array}$ & $\begin{array}{l}\text { Q3-compliance/ } \\
\text { beyond compliance }\end{array}$ & $\begin{array}{l}\text { Q5_-tangible } \\
\text { vs. intangible benefits }\end{array}$ & $\begin{array}{l}\text { Q6-ranking } \\
\text { importance? }\end{array}$ & $\begin{array}{l}\text { Q9_-stakeholder focus or } \\
\text { corporate strategy? }\end{array}$ \\
\hline $\mathrm{C} 1$ & Compliance & $\begin{array}{l}\text { Sustainable products; } \\
\text { reputation; retention }\end{array}$ & No (change in CEO) & Combination \\
\hline $\mathrm{C} 2$ & Compliance & Intangible & Yes & Combination \\
\hline $\mathrm{C} 3$ & Compliance & Intangible & Yes & Combination \\
\hline $\mathrm{C} 4$ & Compliance & Intangible & Yes & Combination \\
\hline E1 & Compliance & Intangible & Yes & Combination \\
\hline $\mathrm{F} 1$ & Compliance & Intangible & Yes & Combination \\
\hline F2 & Compliance & Intangible & Yes & Combination \\
\hline F3 & Compliance & Intangible & Yes & Combination \\
\hline H1 & Compliance & Intangible & Yes & Combination \\
\hline $\mathrm{H} 2$ & Compliance & Intangible & Yes & Combination \\
\hline I1 & Compliance & Intangible & Yes & Combination \\
\hline $\mathrm{I} 2$ & Compliance & Environmental impacts & Yes & Combination \\
\hline $\mathrm{I} 3$ & Compliance & Intangible & Yes & Combination \\
\hline I4 & Compliance & Intangible & Yes & Combination \\
\hline I5 & Compliance & Intangible & Yes & Combination \\
\hline I6 & Compliance & Intangible & Yes & Combination \\
\hline I7 & Compliance & Intangible & Yes & Combination \\
\hline M1 & Compliance & Intangible & Yes & Combination \\
\hline M2 & Compliance & Intangible & No & Combination \\
\hline M3 & Compliance & Intangible & Yes & Combination \\
\hline M4 & Compliance & $\begin{array}{l}\text { Intangible; tangible in } \\
\text { environment }\end{array}$ & Yes & Combination \\
\hline M5 & Compliance & Intangible & Yes & Combination \\
\hline $\mathrm{P} 1$ & Compliance & Intangible & Yes & Combination \\
\hline $\mathrm{R} 1$ & Compliance & Intangible & Yes & Combination \\
\hline R2 & Compliance & Intangible & Yes & Combination \\
\hline R3 & Compliance & Intangible & Yes & Combination \\
\hline R4 & Compliance & Intangible & Yes & Combination \\
\hline $\mathrm{T} 1$ & Compliance & Intangible & Yes & Combination \\
\hline $\mathrm{T} 2$ & Compliance & Intangible & Yes & Combination \\
\hline $\mathrm{T} 3$ & Compliance & $\begin{array}{l}\text { Costs; opportunities; } \\
\text { employment }\end{array}$ & Yes & Combination \\
\hline $\mathrm{T} 4$ & Compliance & Intangible & Yes & Combination \\
\hline T5 & Compliance & $\begin{array}{l}\text { Costs (GHGE); } \\
\text { visibility }\end{array}$ & No & Combination \\
\hline T6 & Compliance & Intangible & Yes & Combination \\
\hline $\mathrm{T} 7$ & Compliance & Intangible & No & Combination \\
\hline U1 & Compliance & $\begin{array}{l}\text { Intangible; tangible in } \\
\text { environment }\end{array}$ & Yes & Combination \\
\hline
\end{tabular}


Table 8 Integration and social measurement of TBL

\begin{tabular}{|c|c|c|c|}
\hline $\begin{array}{l}\text { Company } \\
\text { coding }\end{array}$ & $\begin{array}{l}\text { Q8-full } \\
\text { integration }\end{array}$ & Q10-importance of social area & Q11—social net profit/loss? \\
\hline Al & No & Yes & No, too many assumptions \\
\hline A2 & No & Yes & No \\
\hline A3 & No & Yes & No, not our problem \\
\hline B1 & No & Yes & No, little value \\
\hline B2 & No & Yes & No \\
\hline $\mathrm{C} 1$ & No & Yes & No \\
\hline $\mathrm{C} 2$ & No & Yes, less than environment & No \\
\hline $\mathrm{C} 3$ & No & Not major concern & No \\
\hline $\mathrm{C} 4$ & No & Yes & No \\
\hline E1 & No & Yes & No, treat people as people \\
\hline $\mathrm{F} 1$ & No & Yes & No \\
\hline $\mathrm{F} 2$ & No & Yes & No, not an algorithm \\
\hline F3 & No & Yes & No \\
\hline H1 & No & Yes & No \\
\hline $\mathrm{H} 2$ & No & Yes & No, cannot be precise \\
\hline I1 & No & Yes & No \\
\hline $\mathrm{I} 2$ & No & Yes & No, not meaningful \\
\hline I3 & No & Yes & $\begin{array}{l}\text { No, good for benchmarking } \\
\text { but no real purpose }\end{array}$ \\
\hline I4 & No & Yes, less than environment & No \\
\hline I5 & No & Yes, less than environment & No, little value \\
\hline I6 & No & Yes & No \\
\hline I7 & No & $51 \%$ environment, $49 \%$ social & Dangerous \\
\hline M1 & No & Yes, less than environment & No, should not be financial \\
\hline M2 & No & Yes & No, not useful \\
\hline M3 & No & Yes & No \\
\hline M4 & No & Yes & No, too many assumptions \\
\hline M5 & No & Yes & No \\
\hline P1 & No & Yes & Ludicrous \\
\hline R1 & No & Yes, measure what can be measured & No \\
\hline $\mathrm{R} 2$ & No & Yes & No, more of a story \\
\hline R3 & No & Yes & No \\
\hline R4 & No & Yes, measure what can be measured & No \\
\hline $\mathrm{T} 1$ & No & Yes & No \\
\hline $\mathrm{T} 2$ & No & Yes & No \\
\hline $\mathrm{T} 3$ & No & Yes & No \\
\hline $\mathrm{T} 4$ & No & Yes & No value for business \\
\hline T5 & No & Yes; less than environment & Unconsciously incompetent \\
\hline T6 & No & Yes & No \\
\hline $\mathrm{T} 7$ & No & Only safety, environment is more important & No idea \\
\hline U1 & No & Yes & No \\
\hline
\end{tabular}


Table 9 Motivation and future of reporting

Company coding Q14-prosperity or responsibility? Q17—future

TBL drove prosperity; beyond TBL drives responsibility

TBL drove prosperity; beyond TBL drives responsibility

TBL drove prosperity; beyond TBL drives responsibility

TBL drove prosperity; beyond TBL drives responsibility

TBL drove prosperity; beyond TBL drives responsibility

Leadership; prosperity; stakeholder pressures

TBL drove prosperity; beyond TBL drives responsibility

TBL drove prosperity; beyond TBL drives responsibility

TBL drove prosperity; beyond TBL drives responsibility

TBL drove prosperity; beyond TBL drives responsibility

TBL drove prosperity; beyond TBL drives responsibility

TBL drove prosperity; beyond TBL drives responsibility

TBL drove prosperity; beyond TBL drives responsibility

TBL drove prosperity; beyond TBL drives responsibility

TBL drove prosperity; beyond TBL drives responsibility

TBL drove prosperity; beyond TBL drives responsibility

TBL drove prosperity; beyond TBL Stated goals; less fuzz drives responsibility

TBL drove prosperity; beyond TBL Integration; social accounting drives responsibility

TBL drove prosperity; beyond TBL drives responsibility

TBL drove prosperity; beyond TBL drives responsibility

TBL drove prosperity; beyond TBL drives responsibility

TBL drove prosperity; beyond TBL drives responsibility

TBL drove prosperity; beyond TBL drives responsibility

TBL drove prosperity; beyond TBL drives responsibility
Automation; online

Certain level of integration; still tell a story

Life-cycle approach

Accountability rather than materiality

Bringing information together

Backwards to compliance

Stakeholder assessment

Materiality; embedding into culture

Engagement and feedback

Accountability and transparency

Ongoing process; online

Integrated reporting

Integration; timing by alignment

Alignment to strategic priorities

Integration

Process focused approach

Integration; social accounting

Integration; regulation

Stakeholder feedback; quantitative results

Fixed and quantitative (for social)

Having a standalone report
Work as a whole 
Table 9 (continued)

\begin{tabular}{|c|c|c|}
\hline Company coding & Q14_prosperity or responsibility? & Q17-future \\
\hline M3 & $\begin{array}{l}\text { TBL drove prosperity; beyond TBL } \\
\text { drives responsibility }\end{array}$ & See the value added \\
\hline M4 & $\begin{array}{l}\text { TBL drove prosperity; beyond TBL } \\
\text { drives responsibility }\end{array}$ & $\begin{array}{l}\text { Improve internally; innovation } \\
\text { management }\end{array}$ \\
\hline M5 & $\begin{array}{l}\text { TBL drove prosperity; beyond TBL } \\
\text { drives responsibility }\end{array}$ & $\begin{array}{l}\text { Embedding sustainability into } \\
\text { corporate culture }\end{array}$ \\
\hline P1 & $\begin{array}{l}\text { TBL drove prosperity; beyond TBL } \\
\text { drives responsibility }\end{array}$ & $\begin{array}{l}\text { Embedding sustainability into } \\
\text { corporate culture }\end{array}$ \\
\hline R1 & $\begin{array}{l}\text { TBL drove prosperity; beyond TBL } \\
\text { drives responsibility }\end{array}$ & $\begin{array}{l}\text { Stakeholder engagement; ethical } \\
\text { sourcing }\end{array}$ \\
\hline R2 & $\begin{array}{l}\text { TBL drove prosperity; beyond TBL } \\
\text { drives responsibility }\end{array}$ & Embedded; real time \\
\hline R3 & $\begin{array}{l}\text { TBL drove prosperity; beyond TBL } \\
\text { drives responsibility }\end{array}$ & $\begin{array}{l}\text { Embedding sustainability into } \\
\text { corporate culture }\end{array}$ \\
\hline R4 & $\begin{array}{l}\text { TBL drove prosperity; beyond TBL } \\
\text { drives responsibility }\end{array}$ & $\begin{array}{l}\text { Stakeholder engagement; ethical } \\
\text { sourcing }\end{array}$ \\
\hline $\mathrm{T} 1$ & $\begin{array}{l}\text { TBL drove prosperity; beyond TBL } \\
\text { drives responsibility }\end{array}$ & Integration; assurance \\
\hline $\mathrm{T} 2$ & $\begin{array}{l}90 \% \text { compliance driven; } 10 \% \\
\text { responsibility }\end{array}$ & $\begin{array}{l}\text { Embedding sustainability into } \\
\text { corporate culture }\end{array}$ \\
\hline $\mathrm{T} 3$ & $\begin{array}{l}\text { TBL drove prosperity; beyond TBL } \\
\text { drives responsibility }\end{array}$ & $\begin{array}{l}\text { Impacts; stakeholder engagement; } \\
\text { online }\end{array}$ \\
\hline $\mathrm{T} 4$ & $\begin{array}{l}\text { TBL drove prosperity; beyond TBL } \\
\text { drives responsibility }\end{array}$ & Automation \\
\hline T5 & $\begin{array}{l}\text { TBL drove prosperity; beyond TBL } \\
\text { drives responsibility }\end{array}$ & Transparency; economic perspectives \\
\hline T6 & $\begin{array}{l}\text { TBL drove prosperity; beyond TBL } \\
\text { drives responsibility }\end{array}$ & Integration; materiality \\
\hline $\mathrm{T} 7$ & $\begin{array}{l}\text { TBL drove prosperity; beyond TBL } \\
\text { drives responsibility }\end{array}$ & New company so baby steps \\
\hline U1 & $\begin{array}{l}\text { TBL drove prosperity; beyond TBL } \\
\text { drives responsibility }\end{array}$ & Stakeholder feedback; quantitative results \\
\hline
\end{tabular}

\section{References}

Berger, I., Cunningham, P., \& Drumwright, M. (2007). Mainstreaming corporate social responsibility: developing markets for review. California Management Review, 49, 132-157.

Blacconiere, W., \& Patten, D. (1994). Environmental disclosure, regulatory costs, and changes in firm value. Journal of Accounting and Economics, 18(3), 357-377.

Clarkson, P. M., Li, Y., Richardson, G. D., \& Vasvari, F. P. (2008). Revisiting the relation between environmental performance and environmental disclosure: an empirical analysis. Accounting, Organizations and Society, 33(4-5), 303-327.

Corporateregister. (2008). The csr assurance statement report. London: Corporate register.

Cumming, J. (2001). Engaging stakeholders in corporate accountability programmes: a cross-sectoral analysis of UK and transnational experience. Business Ethics: A European Review, 10(1), 45-52. 
Cummings, J., \& Doh, J. (2000). Identifying who matters: mapping key players in multiple environments. California Management Review, 42(2), 83-104.

Donaldson, T. (2005). 'Defining the value of doing good business,' Financial Times, June 2, 2005

Dunphy, D., Griffiths, A., \& Ben, S. (2003). Corporational change for corporate sustainability: a guide for leaders and change agents of the future. London: Routledge.

Elkington, J. (1997). Cannibals with forks: the triple-bottom line of 21st century business. London: Capstone.

Etzion, D., \& Ferraro, F. (2009). The role of analogy in the institutionalization of sustainability reporting. Organization Science, 21, 1092-1107.

Friedman, M. (1970). 'The social responsibility of business is to increase its profits,' New York Times

Greening, D., \& Turban, D. (2000). Corporate social performance as a competitive advantage in attracting a quality workforce. Business and Society, 39(3), 254-280.

Greiner, L. (1972). Evolution and revolution as corporations grow. Harvard Business Review, 10(4), 3746.

Gri. 2006. G3 sustainability reporting guidelines. Version for public comment. 2 January 2006-31 March 2006. Available at: http://www.grig3.org. Accessed 30 Jul 2009.

Hart, S. L. (1997). Beyond greening: strategies for a sustainable world. Harvard Business Review, 75(1), 66-76.

Hartman, L. P., Rubin, R. S., \& Dhanda, K. K. (2007). The communication of corporate social responsibility: United States and European Union multinational corporations. Journal of Business Ethics, 74, 373-389.

Healy, P., \& Palepu, K. (2001). 'Information asymmetry, corporate disclosure, and the capital markets: A review of the empirical disclosure literature. Journal of Accounting and Economics, 31, 405-440.

Henriques, A., \& Richardson, J. (2004). The Triple Bottom Line: does it all add up? London: Earthscan.

Hooghiemstra, R. (2000). Corporate communication and impression management - new perspectives why companies engage in corporate social reporting. Journal of Business Ethics, 27(1/2), 55-68.

Hubbard, G. (2009). Measuring organizational performance: beyond the Triple Bottom Line. Business Strategy and the Environment, 18, 177-191.

Jawahar, I. M., \& Mclaughlin, G. L. (2001). Toward a descriptive stakeholder theory: an organizational life cycle approach. Academy of Management Review, 26(3), 397-415.

Kaplan, R., \& Cooper, R. (1998). Cost and effect, using integrated cost systems to drive profitability and performance. Boston: Harvard Business School Press.

Kimmett, P., \& Boyd, T. (2004). An Institutional Understanding of Triple Bottom Line evaluations and the use of social and environmental metrics. Construction innovation project. Brisbane: School of Construction Management and Property.

Macdonald, C., \& Norman, W. (2007). Rescuing the baby from the Triple Bottom Line bathwater: a reply to Pava. Business Ethics Quarterly, 17, 111-114.

Makower, J. (1993). The E-factor: the bottom line approach to environmentally responsible business. New York: Tilden Press.

Mirvis, P. H., \& Googins, B. (2004). The best of the good. Harvard Business Review, 48(2), $20-21$.

Moneva, J., Archel, P., \& Correa, C. (2006). GRI and the camouflaging of corporate unsustainability. Accounting Forum, 30, 121-137.

Morland, M. P. (2006). Triple Bottom Line reporting as social grammar: integrating corporate social responsibility and corporate codes of conduct. Business Ethics: A European Review, 15, 352-364.

Nielsen, A. E., \& Thomsen, C. (2007). Reporting CSR-what and how to say it? Corporate Communications: An International Journal, 12(1), 25-40.

Norman, W., \& Macdonald, C. (2003). Getting to the Bottom of "Triple Bottom Line". Business Ethics Quarterly.

Pedrini, M. (2007). Human capital convergences in intellectual capital and sustainability reports. Journal of Intellectual Capital, 8(2), 346. Retrieved February 1, 2010, from ABI/INFORM Global database. (Document ID: 1344405941).

Piaget, J. (1969). The psychology of the child. New York: Wiley.

Post, J., \& Altman, B. (1992). Models of corporate greening: how corporate social policy and organizational learning inform leading edge environmental management. Research in Corporate Social Performance and Policy, 13, 3-29.

PricewaterhouseCoopers (2003). 'Global CEO Survey 2003', available online at www.pwcglobal.com

Raar, J. (2002). Environmental initiatives: towards Triple Bottom Line reporting. Corporate Communications: An International Journal, 7, 169-183. 
Roberts, R. (1992). Determinants of corporate social responsibility disclosure: an application of stakeholder theory. Accounting Organization and Society, 17(6), 595-612.

Robins, F. (2006). The challenge of TBL: a responsibility to whom? Business and Society Review, 111, $1-14$.

Rondinelli, A., \& Berry, M. A. (1997). Industry's role in air quality improvement: environmental management opportunities for the 21st century. Environmental Quality Management, 7, 31-44.

Savitz, A., \& Weber, K. (2006). The Triple Bottom Line: how today's best run companies are achieving economic, social, and environmental success - and how you can too. San Francisco: Wiley.

Schaltegger, S., \& Burritt, R. L. (2000). Contemporary environmental accounting-issues, concepts and practice. Sheffield: Greenleaf publishing.

Schoenberger-Orgad, M., \& Mckie, D. (2005). Sustaining edges: CSR, postmodern play, and SMEs. Public Relations Review, 31, 578-583.

Sherman, W. R. (2008). The global reporting initiative: what value is added? International Business \& Economics Journal, 8(5), 9-21.

Sherman, W. R. (2009). Making Triple Bottom Line reporting comparable: adoption of the GRI G3 framework. Presented at 2009 Oxford Business \& Economics Conference, Oxford, UK, 25 June 2009.

Shrivastava, P. (1992). Corporate self-greenewal: strategic responses to environmentalism. Business Strategy and the Environment, 1(3), 9-21.

Sridhar, K. (2011). A multi-dimensional criticism of the Triple Bottom Line reporting approach. International Journal of Business Governance and Ethics, 6(1), 49-67.

Sullivan, T. F. P. (Ed.). (1992). The greening of American business making bottom line sense of environmental responsibility. Rockville: Government Institutes, Inc.

Van de Ven, A., \& Poole, M. S. (1995). Explaining development and change in organizations. Academy of Management Review, 20, 510-540.

Verrecchia, R. (1993). How do we assess a model of price and volume? The Accounting Review, 68(4), $870-873$.

Wheelan, S. A. (2004). Group processes: a developmental perspective. Sydney: Allyn \& Bacon.

Zadek, S. (2004). The path to corporate responsibility. Harvard Business Review, 82(12), 125-133. 